Article

\title{
Interactions among the Predatory Midge Aphidoletes aphidimyza (Diptera: Cecidomyiidae), the Fungal Pathogen Metarhizium brunneum (Ascomycota: Hypocreales), and Maize-Infesting Aphids in Greenhouse Mesocosms
}

\author{
Ana Gorete Campos de Azevedo, Bernhardt Michael Steinwender, Jørgen Eilenberg and \\ Lene Sigsgaard * \\ Department of Plant and Environmental Science, University of Copenhagen, 1871 Frederiksberg C, Denmark; \\ agca@plen.ku.dk (A.G.C.d.A.); b.steinwender@t-online.de (B.M.S.); jei@plen.ku.dk (J.E.) \\ * Correspondence: les@plen.ku.dk; Tel.: +45-35-33-26-74
}

Academic Editors: Andrew G. S. Cuthbertson and Eric W. Riddick

Received: 16 November 2016; Accepted: 6 April 2017; Published: 12 April 2017

\begin{abstract}
The generalist entomopathogenic fungus, Metarhizium brunneum, has proved to have great potential as a versatile biological pest control agent. The gall midge Aphidoletes aphidimyza is a specialist predator that occurs naturally in Europe and has been successfully used for aphid suppression. However, the interaction between these two biological control organisms and how it may affect the biological control of aphids awaits further investigation. As part of the EU-supported project INBIOSOIL, this study was conducted in greenhouse conditions to assess the possible effects of combining both biological control agents. In a randomized complete block design, sweet corn (Zea mays var. saccharata) plants were grown in large pots filled with natural soil or natural soil inoculated with $M$. brunneum. At the third leaf stage, before being individually caged, plants were infested with Rhopalosiphum padi and A. aphidimyza pupae were introduced in the soil. Aphidoletes aphidimyza midge emergence, number of living midges and number of aphids were recorded daily. The presence of conidia in the soil and on leaves was assessed during the experiment. At the conclusion of the experiment, the number of live aphids and their developmental stage, consumed aphids, and A. aphidimyza eggs was assessed under stereomicroscope. This study's findings showed that the presence of $M$. brunneum did not affect $A$. aphidimyza midge emergence. However, longevity was significantly affected. As the study progressed, significantly fewer predatory midges were found in cages treated with M. brunneum compared to untreated cages. Furthermore, by the end of the study, the number of predatory midges found in the Metarhizium-treated cages was four times lower than in the untreated cages. Both daily and final count of aphids were significantly affected by treatment. Aphidoletes aphidimyza applied alone suppressed the aphid population more effectively than M. brunneum applied alone. Additionally, the aphid population was most suppressed when both agents were combined, though the suppression was less than additive.
\end{abstract}

Keywords: natural enemies; non-target-effects; pathogen; predator; Aphidoletes aphidimyza; Metarhizium brunneum

\section{Introduction}

Aphids (Hemiptera: Aphididae) are phloem-feeding insects that affect a variety of crops in agriculture including maize, sorghum, wheat and barley [1]. An extensive range of natural enemies, such as entomopathogenic fungi and aphidophagous predators, attacks the aphid community, and 
interactions among these natural enemies can be expected [2]. Rhopalosiphum padi (L.) is one of the most important cereal pests in Denmark and Northern Europe; therefore, using biological control to suppress the aphid population could bring a decrease in pesticide use [3].

Several studies have demonstrated the ability of the entomopathogenic fungi from the genus Metarhizium to suppress aphid populations [4-6]. Additionally, Metarhizium has been found to cause mycoses in an important soil dwelling pest in maize, Diabrotica virgifera (Col., Chrysomelidae) [7], and it shows persistence in maize fields [8]. Metarhizium brunneum GranMet/BIPESCO 5 (Samen Schwarzenberger, Austria), the same genotype as used in this study, is the only strain registered commercially for using against pests in several European countries, officially deposited as ARSEF1095 or DSM3884 [9]. Although there have been studies concerning the non-target effects of Metarhizium on beneficial insects, few have dealt with these effects in more realistic conditions. Most laboratory studies show that beneficial insect populations face low risk from Metarhizium exposure [10-12]. However, the consequences of non-target effects on the success of biological control cannot be neglected and should be investigated more thoroughly.

Aphidoletes aphidimyza (Rondani) is an aphidophagous gall midge that occurs naturally in Europe and has been successfully used in biological control programs against a wide range of aphid species [13]. Females lay eggs on leaves close to aphid colonies; only the larvae are predaceous and crawl on the leaf surface searching for aphid prey. Each larva may consume 3-50 aphids per day, feeding by biting the leg of the aphid and paralyzing them with a toxin before sucking out the body fluids [14].

The effects of combining insect pathogens and arthropod natural enemies for biological control are of high relevance in many crop systems, as complex interactions may occur and impact the final outcome. The release of a biocontrol agent can affect the naturally occurring beneficial insects, causing direct or indirect effects on non-target species. Hence the introduction of multiple agents should be conducted with caution as different types of natural enemies can synergistically control herbivore populations, or they can negatively impact each other [15]. Many studies have investigated non-target effects of fungal pathogens on beneficial insects affecting aphid suppression [16-18]. However, there is a need to assess the non-target effects of fungal pathogens on A. aphidimyza because the focus has mainly been on A. Aphidimyza interacting with other arthropod natural enemies and nematodes [19-21].

As part of the EU FP7 project INBIOSOIL, this study was designed to evaluate the impact of soil applied M. brunneum on A. aphidimyza and the resulting suppression of maize-infesting R. padi. The predator pupates in the soil and thus could be directly exposed to M. brunneum, so it was hypothesized that the fungus could negatively affects the predator, as shown by [22]. It was further hypothesized that natural enemies from two remote functional groups would be complementary in terms of aphid population suppression, as previously found in studies with predators from different functional groups [23].

Considering that multitrophic effects originating from the host plant may greatly affect the results of the trial [24], this setup was developed to provide sufficient scale and complexity for expression of a wide range of potential interspecific interactions and a realistic measure of resulting pest population performance.

\section{Materials and Methods}

\subsection{Source and Maintenance of Insects}

Cohort rearing of A. aphidimyza was carried out by EWH BioProduction ApS (Tappernøje, Denmark) and maintained at $23 \pm 0.5{ }^{\circ} \mathrm{C}, 50 \%-75 \%$ relative humidity and L16: D8 light regime. The company also has a mass-production of this species, complying with the IOBC quality control guidelines for beneficial arthropods [25]. For production of cohorts of A. aphidimyza, males and females were released into a cage $(40 \mathrm{~cm} \times 40 \mathrm{~cm} \times 40 \mathrm{~cm})$ with a pepper plant, infested with Myzus persicae. After $24 \mathrm{~h}$, adults were removed and a whole pepper plant with $A$. aphidimyza eggs was transferred into a tray $(10 \mathrm{~cm} \times 10 \mathrm{~cm} \times 5 \mathrm{~cm})$ and covered with sand. The gall midge larvae emerging from eggs 
were fed daily with $10 \mathrm{~mL}$ of aphids (Megoura sp.) until pupation, which occurs in the sand [26]. For this experiment, 5-6 days old A. aphidimyza pupae were used.

Rhopalosiphum padi was provided on barley banker plants from the same company and maintained in a ventilated plexiglass cage $(0.60 \mathrm{~m} \times 0.30 \mathrm{~m} \times 0.30 \mathrm{~m})$ for one week at $21{ }^{\circ} \mathrm{C}$ until used in the experiment. Pilot tests showed that $R$. padi performed well after being transferred from barley to maize. Only apterous, virginoparous females were used in the experiment.

\subsection{Source and Preparation of the Microbial Inoculum}

Metarhizium brunneum (KVL 12-19) was the strain chosen for this study as part of EU FP7 project INBIOSOIL, representing the same genotype as GranMet/BIPESCO 5. The strain is maintained frozen $\left(-80{ }^{\circ} \mathrm{C}\right)$ at University of Copenhagen, Department of Plant and Environmental Sciences. Stock cultures of the strain were grown on $4 \%$ Sabouraud dextrose agar (SDA; Merck, Sweden) in vented Petri dishes and then stored at $8{ }^{\circ} \mathrm{C}$ for up to six months. Subcultures were grown by transferring conidia from a stock culture plate onto SDA plates and incubating at $20 \pm 1{ }^{\circ} \mathrm{C}$ for 20 days. Conidia were harvested by flooding the cultures with sterile $0.05 \%$ Triton-X 100 (VWR, Stockholm, Sweden), and scraping with a sterile Drigalski spatula and the resulting suspension was transferred to $50 \mathrm{~mL}$ stock tube. Concentrations of the stock suspension were measured in a hemocytometer. To assess conidial viability, germination tests were carried out and viability was determined to be $>95 \%$. Stock suspensions of conidia were refrigerated and used the day after preparation.

\subsection{Soil, Plant Material and Cages}

Soil was obtained from the University of Copenhagen experimental farm Bakkegaarden, which has been managed as an organic farm for at least ten years. Pure, sieved soil from the top $20 \mathrm{~cm}$ was used in the experiment. Sweet corn (Zea mays L.) cv. Sundance, F1 hybrid was used in the experiment.

Experimental cages ( $40 \mathrm{~cm}$ diameter and $1 \mathrm{~m}$ height) were made of plastic Mylar film with the top covered with fine white nylon mesh, firmly fitted on the top of the cage with a plastic ring. In the side of the cage a flap $(10 \mathrm{~cm} \times 20 \mathrm{~cm})$ could be opened to facilitate manipulation in the cage. Cages were made so that they fit tightly into the rim of $20 \mathrm{~L}$ pots (Figure 1 ). The pots were filled with soil and

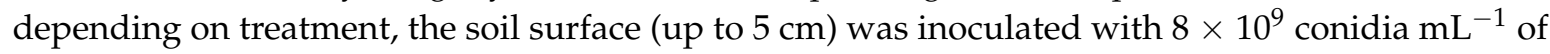
M. brunneum spore suspension or by adding $0.05 \%$ Triton- $X 100$ on the same day the seeds were sown. Three maize seeds were sown per pot and thinned to one plant seven days after sowing. The thinned plants were used for a separate analysis.

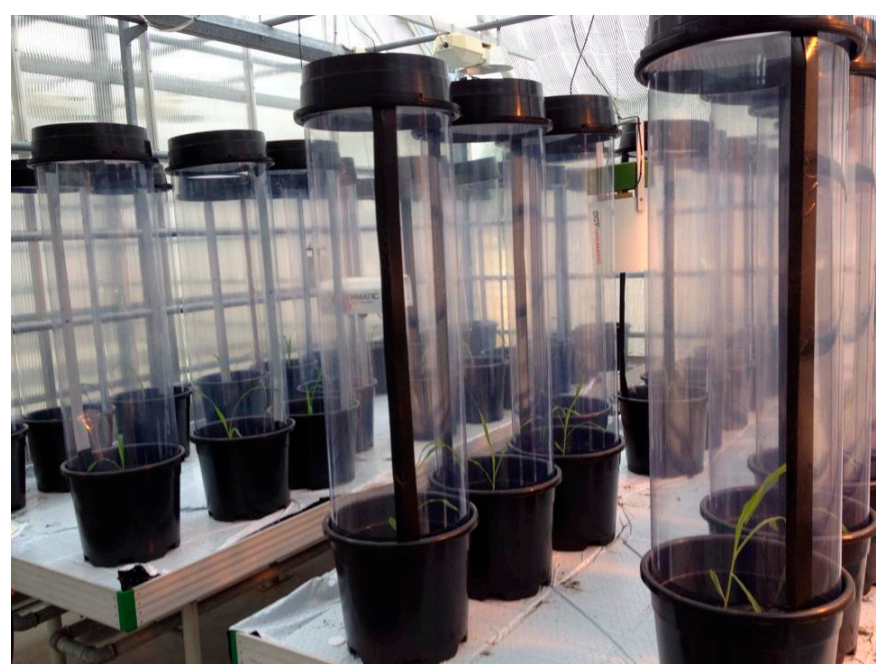

Figure 1. Experimental cages made of plastic Mylar film. Cage tops were covered with fine nylon mesh and secured with plastic rings to prevent insect escape. 


\subsection{Experimental Design}

The experiment was conducted under greenhouse conditions, at $23 \pm 2{ }^{\circ} \mathrm{C}$ and $15 \pm 2{ }^{\circ} \mathrm{C}$, during day and night, respectively, $12 \mathrm{~h}$ with light using supplemental light when necessary, and $80 \%-85 \%$ RH. The irrigation was supplied by bottom watering containing a nutrient solution, an ordinary NPK solution with Electrical conductivity 2.00 and $\mathrm{pH}$ 6.00. After three weeks when the plants had reached the third foliar stage, they were infested with $R$. padi, first by introducing one barley leaf with five adult aphids onto the maize plant and two days later an additional leaf with 10 adult aphids was added to obtain a sufficient aphid infestation. In treatments with $A$. aphidimyza, twenty pupae were introduced into the pot soil on the same day as aphid infestation and A. aphidimyza pupae were positioned equidistantly in $3 \mathrm{~cm}$ depth around each plant in a $10 \mathrm{~cm}$ perimeter (Table 1).

Table 1. The number and date of release of aphids and biological control agents over the course of the experiment.

\begin{tabular}{cccc}
\hline Organism & Release Date & Corresponding Week & Number of Organisms Released \\
\hline M. brunneum (suspension) & 18 March 2015 & 0 & $8 \times 10^{9}$ conidia/pot \\
\hline \multirow{2}{*}{ R. padi (adults) } & 10 April 2015 & 3 & $5 /$ pot \\
& 13 April 2015 & 4 & $10 /$ pot \\
\hline A. aphidimyza (pupae) & 16 April 2015 & 4 & $20 /$ pot \\
\hline
\end{tabular}

Cages were placed covering the top of the pots right after $R$. padi were introduced (day 1). The effects of $A$. aphidimyza and M. brunneum on $R$. padi were evaluated in a completely randomized block design. Each pot, containing one maize plant infested with $R$. padi, represented one replicate and each treatment was represented by 10 pots, totaling 40 pots (Figure 1). There were four treatments in total: control, fungus only, predator only, and fungus and predator combined.

After the introduction of aphids and A. aphidimyza pupae, cages were checked daily. The day of first midge emergence in each cage was noted and the number of midges recorded daily. Aphid count was time consuming so aphids were visually counted in one-fourth of the cages in each treatment daily, without disturbing the plant, thus preventing observers from seeing aphids hidden in the leaf sheets. The experiment was terminated 11 days after the first midge emergence when aphid densities became very low in both predator treatments. For the final assessment, cages were emptied and leaves were examined under the stereomicroscope. This allowed a full count of the number of live aphids and their developmental stage (nymph or adult), consumed aphids, number of A. aphidimyza eggs and adults. Aphidoletes aphidimyza larvae paralyze the aphid before extracting the body contents [27] leaving the empty aphid fixed to the leaf which makes it possible to count with reasonable precision the aphids with signs of predation.

\subsection{Presence of the Microbial Inoculum}

The presence of M. brunneum conidia in the soil was assessed at the end of the experiment by two methods: selective media and insect-bait.

The soil was sampled by removing with a spoon the upper $3 \mathrm{~cm}$ of soil from five pots treated with M. brunneum and five untreated pots, and then placed individually in plastic bags. A sample of $10 \mathrm{~g}$ of soil was mixed with $90 \mathrm{~mL}$ of $0.05 \%$ Triton-X 100 (VWR, Sweden), diluted to $10^{-3}$ and plated on selective medium containing 39 g potato dextrose agar (PDA; Sigma-Aldrich, Hamburg, Germany), $1 \mathrm{~g}$ yeast, $0.5 \mathrm{~g}$ Chloramphenicol, $0.25 \mathrm{~g}$ Cycloheximide, $44 \mu \mathrm{L}$ dodine. The plates were incubated at $23 \pm 1^{\circ} \mathrm{C}$ for 10 days in the dark, and then the presence of $M$. brunneum was verified.

Tenebrio molitor larvae were used as bait insects. Two $155 \mathrm{~mL}$ plastic cups were filled with the soil taken from each pot. Ten T. molitor larvae were put into each cup; subsequently, the closed cups were incubated at $23 \pm 1^{\circ} \mathrm{C}$ in the dark and inverted every day. Dead larvae were surface sterilized 
with $1 \%$ Na-Hypochlorite prior to incubation in moist chamber. Visible external growth of fungi and microscopic examination of fungal mycelium provided the basis for fungal identification.

The presence of M. brunneum conidia on the leaves was also checked superficially and endophytically. For this assessment, the two weeks old plants thinned in the beginning of the experiment were used: five plants from pots treated with M. brunneum and five from untreated pots. The thinned plants were placed in plastic bags, identified by the treatment, and kept in the refrigerator until the next day for evaluation.

The presence of M. brunneum on leaves was assessed by printing both sides of a leaf, two leaves per plant, onto selective medium (the same used for the soil). After 3 weeks at $23 \pm 1{ }^{\circ} \mathrm{C}$, presence or absence of fungi was confirmed. Endophytic presence of $M$. brunneum was assessed by incubating surface sterilized leaves on selective medium. The leaf surface was sterilized by immersion for $2 \mathrm{~min}$ in $0.5 \%$ sodium hypochlorite, $2 \mathrm{~min}$ in $70 \%$ ethanol, rinsed in sterile deionized water three times and dried using sterile filter paper. The outer edges of the leaves were dissected and discarded [28]. The remaining parts were cut into pieces and cultured on selective medium in a Petri plate. Ten plates from each treatment (with and without fungi application) were incubated with three pieces of leaf per plate (two plates per plant). The plates were incubated for three weeks at $23 \pm 1{ }^{\circ} \mathrm{C}$.

\subsection{Molecular Characterization Metarhizium Isolate}

The recovered Metarhizium strain was firstly morphologically identified and then molecularly identified. DNA was extracted from the conidia harvested from one plate using the DNeasy Plant Mini Kit (QIAGEN, Hilden, Germany) following the manufacturer's instructions. PCR amplifications were performed for one representative isolate of each multilocus genotype with primers EF2F (5'-GGAGGACAAGACTCACATCAACG-3') and EFjR (5'-TGYTCNCGRGTYTGNCCRTCYTT-3') using the conditions described by [29]. PCR products were purified using the GFX PCR DNA and Gel band purification kit (GE Healthcare, Little Chalfont, UK) and sequenced with the same primers. Sequencing was performed by Beckman Coulter Genomics (Essex, UK). The sequence was aligned using GenBank.

\subsection{Data Analysis}

Visual counts of nymphs and adult aphids (log-transformed) were analyzed using a linear mixed-effects model (PROC MIXED) (SAS Inst., Cary, NC, USA, 2008). Main effects were treatment, day, and cage. Cage was set as a random factor, and day as a repeated factor. Full models were reduced by backward removal of non-significant interaction effects. Visual counts of midges, in treatments with the presence of predator, were analyzed using a generalized linear mixed-effects model (PROC GLIMMIX) (SAS Institute, 2008). Main effects were treatment, day and cage. Cage was set as a random factor, day as a repeated factor, and a poisson distribution was selected based on Alkaikes information criterion (AIC). The model was reduced by backward removal of non-significant interaction effects.

The final counts of nymph and adult aphids (log-transformed) and of consumed aphids were also analyzed using a linear mixed-effects model (Proc MIXED) with treatment as main effect. Final counts of midges and eggs (all stages log-transformed) were analyzed using a linear mixed effects model (proc MIXED) with treatment as main effect. Aphid mortality due to treatment was estimated as the difference between treatment and control. Individual treatments were compared using least squares means.

To assess whether the effect of the two treatments M. brunneum and A. aphidimyza was additive, a Chi-square analysis was conducted comparing aphid mortality in fungus and predator combined treatment to the sum of aphid mortality in fungus only and predator only treatments. 


\section{Results}

\subsection{Presence of The Microbial Inoculum}

The presence of M. brunneum was confirmed in the soil samples from fungal treated pots. Baited T. molitor larvae yielded Metarhizium spp. infections in $64 \%$ of the larvae from sampled cups, whereas no larvae showed signs of infection in the control. Also, by selective medium, the presence of M. brunneum was confirmed in all soil samples from fungal treated pots. Fungal colonies were not observed on plates from the control.

The presence of M. brunneum was confirmed on the surface of $60 \%$ of printed leaves from plants grown in the fungal treated pots. As expected, the fungus was not isolated on the leaves from the control. No endophytic association was found.

The aligning of the $5^{\prime}$ EF1- $\alpha$ sequence, obtained from Metarhizium isolated on the surface of the maize leaves, with BLAST identified it as Metarhizium brunneum.

\subsection{Impact of M. brunneum on A. aphidimyza}

The emergence of $A$. aphidimyza midges began on the fourth day after the pupae were introduced into the cages-day 4 after aphid introduction. In both treatments with $A$. aphidimyza, midge emergence started on the same day and the numbers of adult midges were not significantly different from the first to the eighth day between both treatments. The numbers of A. aphidimyza midges peaked on the fourth day in the predator only treatment and on the 6th day in the fungus and predator combined treatment (Figure 2). There was a significant interaction effect of treatment $\times$ day on midge numbers $\left(F_{10,180}=10.39, p<0.0001\right)$. Pairwise comparisons showed significant differences between the treatments predator only and fungus and predator combined on the last three days of the study, ninth $(t=2.84, p=0.006, \mathrm{df}=82.02)$, 10th $(t=4.19, p<0.0001, \mathrm{df}=88.2)$ and 11th $(t=5.17, p<0.0001$, $\mathrm{df}=90.8$ ) days after pupae had been introduced to the cages (Figure 2). There was no significant effect of treatment on the number of eggs laid by $A$. aphidimyza female midges $\left(F_{1,18}=0.33, p<0.573\right)$, indicating that the entomopathogen M. brunneum had no significant effect on oviposition.

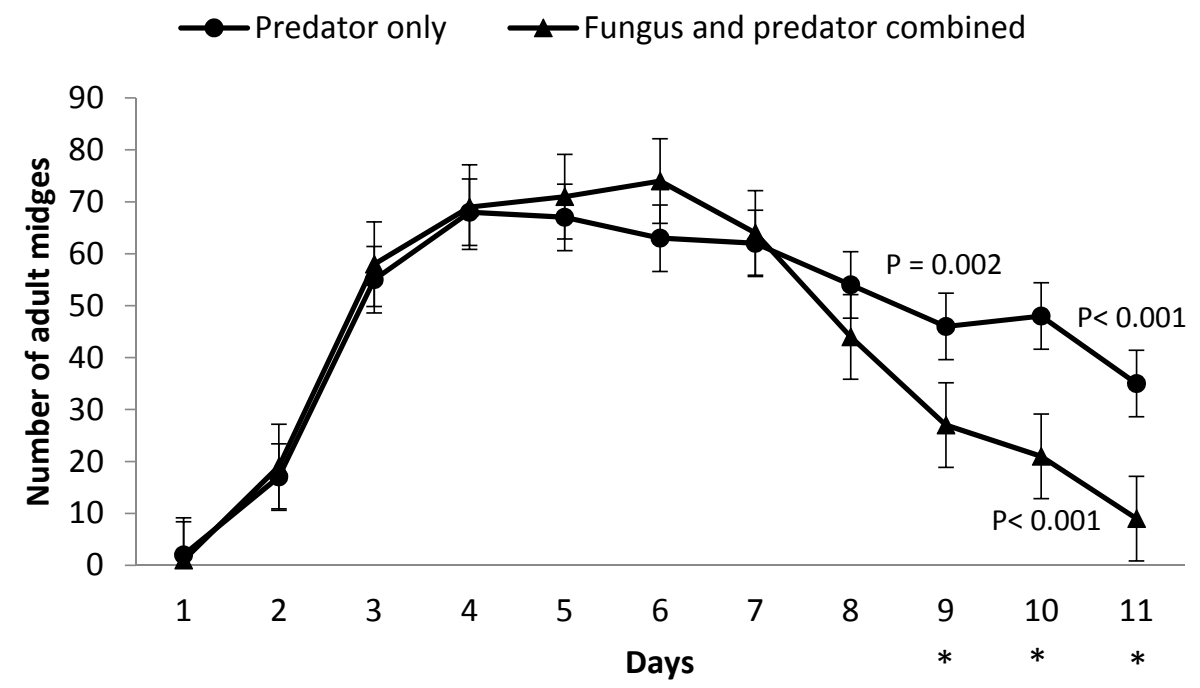

Figure 2. Daily numbers of $A$. aphidimyza midges in the absence (predator only treatment) or presence (fungus and predator combined treatment) of M. brunneum from first day of emergence until last day of experiment. Asterisks indicate statistically significant $(p<0.05)$ differences among treatments.

\subsection{Impact of A. aphidimyza and M. brunneum on R. padi}

The mixed linear model showed a significant effect of treatment $\times$ day on number of aphids (log-transformed) $\left(F_{21,84}=2.94, p=0.0002\right)$. The total number of aphids at the final count also showed 
a significant effect of treatment $\left(F_{3,36}=15.75, p<0.0001\right)$. There were significant effects of $M$. brunneum and A. aphidimyza, separately, on the $R$. padi population $\left(\chi^{2}=56.07, \mathrm{df}=1, p<0.0001, \chi^{2}=537.76\right.$, $\mathrm{df}=1, p<0.0001$, respectively).

The fungus + predator combined treatment suppressed the $R$. padi population significantly compared to the control $(t=4.14, p=0.0002, \mathrm{df}=36$ and $t=6.53, p<0.0001, \mathrm{df}=36$, nymphs and adults respectively).

Rhopalosiphum padi nymph population was significantly affected by treatment $\left(F_{3,36}=26.36\right.$, $p<0.0001)$. Pairwise comparisons showed no significant differences between the control and fungus-only treatment on the $R$. padi population. $(t=1.22, p=0.280, \mathrm{df}=36)$. However, A. aphidimyza suppressed $R$. padi nymphs significantly more than the combined predator + fungi treatment. $(t=-3.97, p=0.0003, \mathrm{df}=36)$ (Figure 3).

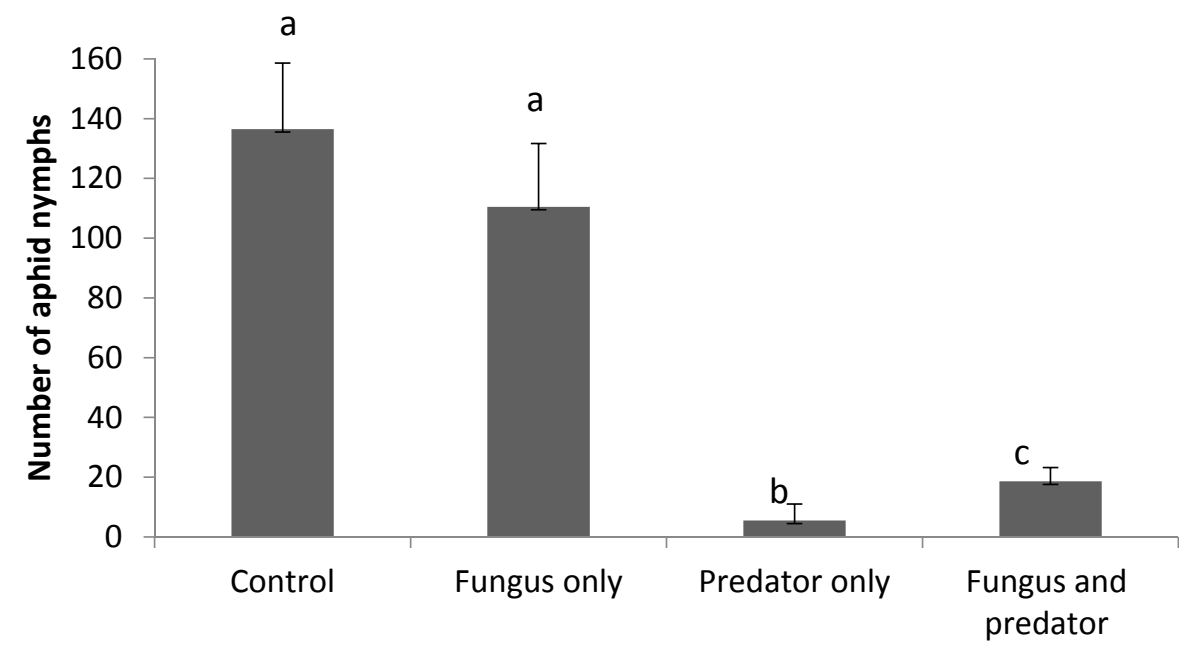

Figure 3. Comparison of the numbers $( \pm \mathrm{SE})$ of living $R$. padi nymphs at the end of the study between treatments treated or untreated with $A$. aphidimyza $(n=40)$ and M. brunneum. Letters above columns indicate significant $(p<0.05)$ differences among treatments.

R. padi adults were significantly influenced by treatment $\left(F_{3,36}=17.21, p<0.0001\right)$. Pairwise comparisons showed no significant differences in the $R$. padi adult population between the control and fungus-only treatment. $(t=1.22, p=0.230, \mathrm{df}=36)$. However, in contrast to $R$. padi nymphs, the adults were suppressed most in the fungus + predator combined treatment rather than the predator-only treatment. $(t=2.42, p=0.020, \mathrm{df}=36)$ (Figure 4$)$. When comparing the fungus-only and predator-only treatments, $R$. padi nymphs and adults were clearly suppressed most by $A$. aphidimyza alone. $(\mathrm{t}=7.01$, $p<0.0001, \mathrm{df}=36$ and $t=2.89, p=0.006, \mathrm{df}=36$, respectively) (Figures 3 and 4). Also, the number of consumed aphids was significantly higher in the predator only treatment than in the fungus and predator combined treatment at the final assessment $(t=3.65, p=0.002, \mathrm{df}=18)$.

The suppression of the aphid population found in the fungus and predator combined treatment was significantly less than the sum of aphid populations from predator only and fungus and predator combined treatments, with the natural enemies applied separately $\left(\chi^{2}=983.8, \mathrm{df}=1, p<0.0001\right)$. 


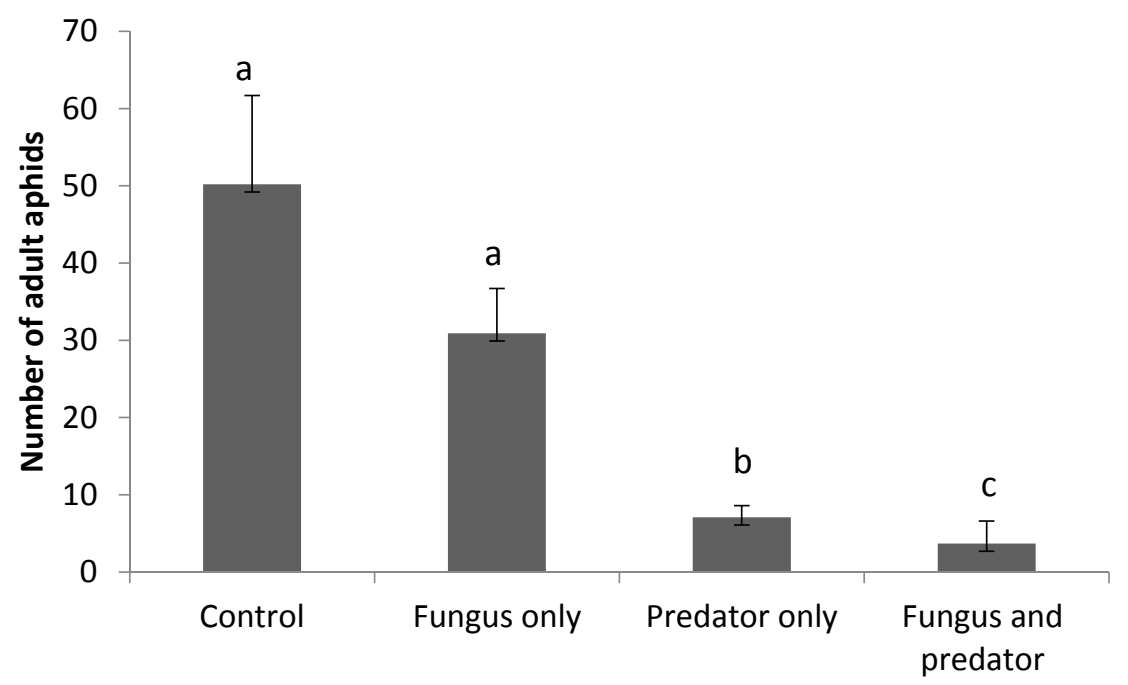

Figure 4. Comparison of the numbers ( \pm SE) of living R. padi adults at the end of the study between treatments treated or untreated with A. aphidimyza $(n=40)$ and M. brunneum. Letters above columns indicate significant $(p<0.05)$ differences among treatments.

\section{Discussion}

It is well known that entomopathogenic fungi are effective microbiological control agents; however, it is essential to ensure that they do not negatively affect non-target organisms, such as beneficial insects. The present study examines, innovatively, the potential impact of an entomopathogenic fungus, $M$. brunneum, applied directly into the soil, on the plant-dwelling aphid R. padi and on the soil-dwelling pupal, adult, egg, and larval stages of the predator A. aphidimyza under greenhouse conditions. The experimental setting simulated a situation in which A. aphidimyza pupae were exposed to soil with high fungal concentration, newly hatched adults emerged through the soil to lay eggs on maize plants infested by aphids; therefore, this greenhouse study represents a multitrophic plant-fungus-insect context.

The observed reduction in adult aphid population in the M. brunneum treatment may have been caused by fungal presence on the surface of the maize leaves. The presence of $M$. brunneum conidia on the surface the leaves was confirmed and it may have occurred during plant growth through the soil or by transportation from soil to leaves by insects. According to [30], aphids are able to distribute entomopathogenic fungi from soil to leaves, this is an evidence of the plant- or insectmediated interactions between fungi in soil and plant-living insects. It is well known that direct fungal application can affect the aphid survival rates and the number of offspring produced per aphid female per day [31,32], while no other studies investigated of soil applied M. brunneum.

Diversity of natural enemies improves biological control of a shared pest if they are complementary [33]. Effects of Beauveria bassiana on parasitoids of the green peach aphid, Aphidius matricariae and Aphidius colemani, have been investigated respectively by [34,35]. The authors found, in both studies, that with appropriate timing, the parasitoids and B. bassiana could be combined for the biological control of M. persicae. These studies showed that the combination of biological control agents requires effective time management to avoid antagonistic interactions. We obtained better control in the combined treatment, but the effect was less than additive, pointing to an antagonistic effect of M. brunneum on A. aphidimyza. Also, the suppression of the aphid population was significantly less in the fungus and predator combined treatment than the sum of aphid populations from predator only and fungus and predator combined treatments. Therefore, use of M. brunneum requires consideration of both timing and method of application to protect non-target predators.

It was hypothesized that $A$. aphidimyza would be exposed to a pathogen on two occasions, during its pupal stage in the soil, especially when the young adult emerged, and again when the adult and its 
offspring came into contact with the plant/aphids. As expected, the initial number of A. aphidimyza adult midges emerging was similar in control and $M$. brunneum-treated cages, suggesting that the fungus did not readily infect the predator in its pupal stage. Aphidoletes aphidimyza pupae are covered by a cocoon structure which impedes natural enemy attacks and provides anti-bacterial and anti-fungal protection [36].

Though the number of adult midges in the predator only treatment peaked two days before the fungus and predator combined treatment, the number of midges in the fungus and predator combined treatment began to decline before then predator only treatment and on the last day of experiment, the predator only treatment had four times more midges than the fungus and predator combined treatment. The suppressed final total number of midges, as well as the later peak and earlier decline of midge numbers in the fungus and predator combined treatment may represent effects of the presence of M. brunneum in this system. Considering that $A$. aphidimyza midges have a life span of approximately seven days and most males emerge before females [37], a decrease in male longevity can be critical for successful mating and can thus directly affect reproduction. Culicoides biting midges (Diptera: Ceratopogonidae), vectors of several arboviruses, showed high larval mortality when exposed directly to M. anisopliae [38]. According to [39], all Culicoides biting midges were found to be infected by M. anisopliea four days after being exposure to a tissue paper dusted with "dry" conidia of the fungi. Aphidoletes aphidimyza midgelongevity can be affected by the content of the honeydew produced by different aphid species and female longevity affects lifetime fecundity [40]. However, little is known about $A$. aphidimyza longevity and the factors that can affect it, especially when combined with fungal pathogens.

The higher number of aphid nymphs in the fungus and predator combined treatment and higher number of aphids consumed in predator only treatment can be considered a consequence of the delay in A. aphidimyza life cycle (or emergence) in the fungus and predator combined treatment due to the M. brunneum presence. It was assumed that in the predator only treatment egg laying commenced earlier than in the fungus and predator combined treatment. The A. aphidimyza predation rate can be affected by other external factors such as the presence of a generalist predator and different $\mathrm{N}$ fertilization levels as showed by [41].

There is a lack of studies combining A. aphidimyza with fungal pathogens. According to [42], A. aphidimyza is compatible with the entomopathogenic fungi Lecanicillium logisporum. However, the report includes no methodological or experimental information.

In a wider perspective, the application of entomopathogenic fungi brings many benefits to maize crops such as controlling $D$. virgifera, a root damaging pest. Considering the situation where, besides aphid pest, other pests are attacking the plant, such as D. virgifera that causes significant high mortality [43], the application of the entomopathogenic fungi would be encouraged even though some negative side-effect of the fungus on A. aphidimyza and other naturally occurring or mass-released predators would be expected, as long as the biocontrol of aphids was still achieved, or even with less effect on aphids if the soil living pest was the major cause of losses.

\section{Conclusions}

Based on the results of this study, A. aphidimyza predation is more effective than M. brunneum in suppressing and controlling $R$. padi population on maize plants. Combining A. aphidimyza and M. brunneum showed an effect on $R$. padi, though the M. brunneum was applied to the soil. The combined effect on $R$. padi was less than additive, and an earlier decline in the number of adult midges was a negative side-effects on A. aphidimyza. For biocontrol purposes, the side-effects of soil application of M. brunneum on the performance of A. aphidimyza can be considered minor.

Acknowledgments: The study was part of the EU project INBIOSOIL (http: / /inbiosoil.uni-goettingen.de), funded by means of the 7th Framework Programme of the European Union 282767. The authors would like to thank Erik W. Hansen and Desislava Dimitrova, EWH BioProduction for the cohorts; the statistician Anders Jensen; the laboratory technician Kristian Hanse; the PhD student Elizabeth Cassidy for the support with the grammar; 
the greenhouse crew at Faculty of Science-Højbakkegård; and three anonymous reviewers for comments and discussion. This study was supported by the INBIOSOIL project and Science without Borders-Brazil.

Author Contributions: Ana Gorete Campos de Azevedo: Planned and executed the experiments; wrote the manuscript. Bernhardt Michael Steinwender: Contributed with ideas for the setup and experimental design. Jørgen Eilenberg: Contributed with ideas for the setup and experimental design; revised the manuscript. Lene Sigsgaard: Analyzed the data; contributed with ideas for the setup and experimental design; revised the manuscript.

Conflicts of Interest: The authors declare no conflict of interest.

\section{References}

1. Smith, C.M.; Chuang, W.P. Plant resistance to aphid feeding: Behavioral, physiological, genetic and molecular cues regulate aphid host selection and feeding. Pest Manag. Sci. 2014, 70, 528-540. [CrossRef] [PubMed]

2. Van Veen, F.J.F.; Müller, C.B.; Pell, J.K.; Godfray, H.C.J. Food web structure of three guilds of natural enemies: Predators, parasitoids and pathogens of aphids. J. Anim. Ecol. 2008, 77, 191-200. [CrossRef] [PubMed]

3. Sigsgaard, L. A survey of aphids and aphid parasitoids in cereal fields in Denmark, and the parasitoids' role in biological control. J. Appl. Entomol. 2002, 126, 101-107. [CrossRef]

4. Shang, L.T.; Feng, M.G. Evaluation of the biocontrol potential of various Metarhizium isolates against green peach aphid Myzus persicae (Homoptera: Aphididae). Pest Manag. Sci. 2010, 66, 669-675.

5. Akmal, M.; Freed, S.; Malik, M.N.; Gul, H.T. Efficacy of Beauveria bassiana (Deuteromycotina: Hypomycetes) against different aphid species under laboratory conditions. Pak. J. Zool. 2013, 45, 71-78.

6. Jandricic, S.E.; Filotas, M.; Sanderson, J.P.; Wraight, S.P. Pathogenicity of conidia-based preparations of entomopathogenic fungi against the greenhouse pest aphids Myzus persicae, Aphis gossypii, and Aulacorthum solani (Hemiptera: Aphididae). J. Invertebr. Pathol. 2014, 118, 34-46. [CrossRef] [PubMed]

7. Pilz, C.; Wegensteiner, R.; Keller, S. Natural occurrence of insect pathogenic fungi and insect parasitic nematodes in Diabrotica virgifera virgifera populations. Biocontrol 2008, 53, 353-359. [CrossRef]

8. Pilz, C.; Enkerli, J.; Wegensteiner, R.; Keller, S. Establishment and persistence of the entomopathogenic fungus Metarhizium anisopliae in maize fields. J. Appl. Entomol. 2011, 135, 393-403. [CrossRef]

9. Eckard, S.; Ansari, M.A.; Bacher, S.; Butt, T.M.; Enkerli, J.; Grabenweger, G. Virulence of in vivo and in vitro produced conidia of Metarhizium brunneum strains for control of wireworms. Crop Prot. 2014, 64, 137-142. [CrossRef]

10. Husberg, G.B.; Heikki, M.T.H. Effects of Metarhizium anisopliae on the pollen beetle Meligethes aeneus and its parasitoids Phradis morionellus and Diospilus capito. BioControl 2001, 46, 261-273. [CrossRef]

11. Jarrahi, A.; Safavi, S.A. Sublethal effects of Metarhizium anisopliae on life table parameters of Habrobracon hebetor parasitizing Helicoverpa armigera larvae at different time intervals. BioControl 2016, 6, 167-175. [CrossRef]

12. Rännbäck, L.M.; Cotes, B.; Anderson, P.; Rämert, B.; Meyling, N.V. Mortality risk from entomopathogenic fungi affects oviposition behavior in the parasitoid wasp Trybliographa rapae. J. Invertebr. Pathol. 2015, 31, 78-86. [CrossRef] [PubMed]

13. Solomon, M.G.; Cross, J.V.; Fitzgerald, J.D.; Campbell, C.A.M.; Jolly, R.L.; Olszak, R.W.; Niemczyk, E.; Vogt, H. Biocontrol of pests of apples and pears in northern and central Europe-3. Predators. Biocontrol Sci. Technol. 2000, 10, 91-128. [CrossRef]

14. Stara, J.; Ourednickova, J.; Kocourek, F. Laboratory evaluation of the side effects of insecticides on Aphidius colemani (Hymenoptera: Aphidiidae), Aphidoletes aphidimyza (Diptera: Cecidomyiidae), and Neoseiulus cucumeris (Acari: Phytoseidae). J. Pest. Sci. 2011, 84, 25-31. [CrossRef]

15. Denoth, M.; Frid, L.; Myers, J.H. Multiple agents in biological control: Improving the odds? Biol. Control 2002, 24, 20-30. [CrossRef]

16. Askary, H.; Brodeur, J. Susceptibility of Larval Stages of the Aphid Parasitoid Aphidius nigripes to the Entomopathogenic Fungus Verticillium lecanii. J. Invertebr. Pathol. 1999, 73, 129-132. [CrossRef] [PubMed]

17. Mesquita, A.L.; Lacey, L.A. Interactions among the entomopathogenic fungus, Paecilomyces fumosoroseus (Deuteromycotina: Hyphomycetes), the parasitoid, Aphelinus asychis (Hymenoptera: Aphelinidae), and their aphid host. Biol. Control 2001, 22, 51-59. [CrossRef]

18. Aqueel, M.A.; Leather, S.R. Virulence of Verticillium lecanii (Z.) against cereal aphids; does timing of infection affect the performance of parasitoids and predators? Pest Manag. Sci. 2013, 69, 493-498. [CrossRef] [PubMed] 
19. Grasswitz, T.R.; Burts, E.C. Effect of native natural enemies and augmentative releases of Chrysoperla rufilabris Burmeister and Aphidoletes aphidimyza (Rondani) on the population dynamics of the green apple aphid, Aphis pomi De Geer. Int. J. Pest Manag. 1995, 41, 176-183. [CrossRef]

20. Hindayana, D.; Meyhöfer, R.; Scholz, D.; Poehling, H.M. Intraguild predation among the hoverfly Episyrphus balteatus De Geer (Diptera: Syrphidae) and other aphidophagous predators. Biol. Control 2001, 20, 236-246. [CrossRef]

21. Powell, J.R.; Webster, J.M. Interguild antagonism between biological controls: Impact of entomopathogenic nematode application on an aphid predator, Aphidoletes aphidimyza (Diptera: Cecidomyiidae). Biol. Control 2004, 30, 110-118. [CrossRef]

22. Wu, S.; Gao, Y.; Smagghe, G.; Xu, X.; Lei, Z. Interactions between the entomopathogenic fungus Beauveria bassiana and the predatory mite Neoseiulus barkeri and biological control of their shared prey/host Frankliniella occidentalis. Biol. Control 2016, 98, 43-51. [CrossRef]

23. Carvalho, V.F.P.; Vacari, A.M.; Pomari, A.F.; Bortoli, C.D.; Ramalho, D.G.; Bortoli, S.D. Interaction between the predator Podisus nigrispinus (Hemiptera: Pentatomidae) and the entomopathogenic bacteria Bacillus thuringiensis. Environ. Entomol. 2012, 41, 1454-1461. [CrossRef] [PubMed]

24. Cory, J.S.; Ericsson, J.D. Fungal entomopathogens in a tritrophic context. BioControl 2010, 55, 75-88. [CrossRef]

25. Van Lenteren, J.C. (Ed.) Quality Control and Production of Biological Control Agents: Theory and Testing Procedures; CABI Publishing: Wallingford, UK, 2003. Available online: http://users.ugent.be/ padclerc/AMRQC/ proceedings/QCflyer.doc (accessed on 15 January 2016).

26. Sigsgaard, L.; Steinwender, B.M.; Dimitrova, D.; Hansen, E.W.; Eilenberg, J. Technical Protocol for Tests of Direct and Indirect Side-Effects of New BCA Formulations on Non-Target Invertebrates. Available online: http:/ / inbiosoil.uni-goettingen.de/fileadmin/INBIOSOIL/Deliverables/3.1\%20Defined\% 20technical\%20protocol\%20for\%20test\%20of\%20side\%20effects\%20....pdf (accessed on 10 November 2016).

27. Lucas, É.; Coderre, D.; Brodeur, J. Intraguild predation among aphid predators: Characterization and influence of extraguild prey density. Ecology 1998, 79, 1084-1092. [CrossRef]

28. Parsa, S.; Ortiz, V.; Vega, F.E. Establishing fungal entomopathogens as endophytes: Towards endophytic biological control. JoVE J. Vis. Exp. 2013, 74, e50360. [CrossRef] [PubMed]

29. Meyling, N.V.; Pilz, C.; Keller, S.; Widmer, F.; Enkerli, J. Diversity of Beauveria spp. isolates from pollen beetles Meligethes aeneus in Switzerland. J. Invertebr. Pathol. 2012, 109, 76-82. [CrossRef] [PubMed]

30. Meyling, N.V.; Pell, J.K.; Eilenberg, J. Dispersal of Beauveria bassiana by the activity of nettle insects. J. Invertebr. Pathol. 2006, 93, 121-126. [CrossRef] [PubMed]

31. Ganassi, S.; Grazioso, P.; Moretti, A.; Sabatini, M.A. Effects of the fungus Lecanicillium lecanii on survival and reproduction of the aphid Schizaphis graminum. Biocontrol 2010, 55, 299-312. [CrossRef]

32. Rashki, M.; Shirvani, A. The effect of entomopathogenic fungus, Beauveria bassiana on life table parameters and behavioural response of Aphis gossypii. Bull. Insectol. 2013, 66, 85-91.

33. Crowder, D.W.; Jabbour, R. Relationships between biodiversity and biological control in agroecosystems: Current status and future challenges. Biol. Control 2014, 75, 8-17. [CrossRef]

34. Rashki, M.; Kharazi-Pakdel, A.; Allahyari, H.; Van Alphen, J.J.M. Interactions among the entomopathogenic fungus, Beauveria bassiana (Ascomycota: Hypocreales), the parasitoid, Aphidius matricariae (Hymenoptera: Braconidae), and its host, Myzus persicae (Homoptera: Aphididae). Biol. Control 2009, 50, 324-328. [CrossRef]

35. Emami, F.; Alichi, M.; Minaei, K. Interaction between the entomopathogenic fungus, Beauveria bassiana (Ascomycota: Hypocreales) and the parasitoid wasp, Aphidius colemani Viereck (Hymenoptera: Braconidae). J. Entomol. Acarol. Res. 2013, 45, 4. [CrossRef]

36. Danks, H.V. The roles of insect cocoons in cold conditions. Eur. J. Entomol. 2004, 101, 433-438. [CrossRef]

37. Van Lenteren, J.C.; Schettino, M.; Isidoro, N.; Romani, R.; Schelt, J. Morphology of putative female sex pheromone glands and mating behavior in Aphidoletes aphidimyza. Entomol. Exp. Appl. 2002, 102, 199-209. [CrossRef]

38. Ansari, M.A.; Carpenter, S.; Butt, T.M. Susceptibility of Culicoides biting midge larvae to the insect-pathogenic fungus, Metarhizium anisopliae: Prospects for bluetongue vector control. Acta Trop. 2010, 113, 1-6. [CrossRef] [PubMed] 
39. Ansari, M.A.; Pope, E.C.; Carpenter, S.; Scholte, E.J.; Butt, T.M. Entomopathogenic fungus as a biological control for an important vector of livestock disease: The Culicoides biting midge. PLoS ONE 2011, 6, e16108. [CrossRef] [PubMed]

40. Higashida, K.; Yano, E.; Toyonishi, H.; Nakauchi, M.; Abe, J. Reproduction of Aphidoletes aphidimyza (Diptera: Cecidomyiidae) on a banker plant system of sorghum with Melanaphis sacchari (Hemiptera: Aphididae) and its oviposition selection between this system and eggplant with Aphis gossypii (Hemiptera: Aphididae). Appl. Entomol. Zool. 2017, 1-9. [CrossRef]

41. Hosseini, M.; Ashouri, A.; Enkegaard, A.; Weisser, W.W.; Goldansaz, S.H.; Mahalati, M.N.; Sarraf Moayeri, H.R. Plant quality effects on intraguild predation between Orius laevigatus and Aphidoletes aphidimyza. Entomol. Exp. Appl. 2010, 135, 208-216. [CrossRef]

42. Goettel, M.S.; Alma, C.; Jaramillo, P.; Kim, J.J.; Gillespie, D.; Roitberg, B. Entomopathogenic fungi in greenhouse ecosystems: Present and future roles. J. Anhui Agric. Univ. 2007, 2, 157-161.

43. Pilz, C.; Wegensteiner, R.; Keller, S. Selection of entomopathogenic fungi for the control of the western corn rootworm Diabrotica virgifera virgifera. J. Appl. Entomol. 2007, 131, 426-431. [CrossRef]

(C) 2017 by the authors. Licensee MDPI, Basel, Switzerland. This article is an open access article distributed under the terms and conditions of the Creative Commons Attribution (CC BY) license (http:/ / creativecommons.org/licenses/by/4.0/). 